\title{
WOMEN IN CARDIOLOGY- CHALLENGES AND OPPORTUNITIES
}

\author{
Rama Bala
}

Congratulations to all women in Cardiology - we have come a long way!

Despite the long history of women providing medical care over centuries, the first woman to be formally trained in medicine was not until the end of 19th century. Women were not allowed entry into medical schools as they were considered to be physically and intellectually inferior. It was thanks to the courage of pioneers like Elizabeth Blackwell, Rebecca Lee Crumpler and Elizabeth Garrett that women emerged as qualified doctors. In fact one of the women pioneers, D r Margaret Buckley had to dress as a man to gain admission to medical school in UK in the19th century. Considering that the first woman cardiologist was not trained till 1960s in Switzerland, one can appreciate the long journey women had to undertake to be accepted as cardiologists. Even in the 21st century, the statistics show that less than $25 \%$ of cardiologists were women and less than a third of these are interventionists. If you take the fact that nearly $60 \%$ of women admitted to medical schools are women, these figures further highlight the discrepancies.

Obstetrics and Paediatrics were the only specialities thought to be 'suitable' for women until the mid-20th century, especially in India. Even general medicine was thought to be a departure from the norm. Paradoxically,

Dr Padmavathy established herself as Cardiologist in Delhi in early 1950s, which is no mean feat.

The greatest obstacle for women to take up cardiology is, in my opinion, this stereotyping itself. It is easy to accept the norm and go with the flow, which is less stressful and probably more 'successful'. However, if you define success as achieving ones full potential, then perhaps women doctors are the ones who compromise the most.

Quite often, woman's role as homemaker is argued as the reason for not entering a male dominated specialty. But in truth, is it not more onerous to be an Obstetrician with emergencies which are unpredictable and which cannot be hurried?

Having to work unsociable hours is again not unique to Cardiology and probably more so in the 'traditional' specialities alike.

Working in a male dominated environment is probably what discourages women most.

If you take a look around you, actually you will find that apart from the doctors, most of the staff on your wards or catheterization laboratory are women - nurses, technicians, radiographers etc. Exposure to radiology is another commonly perceived hurdle. But with modern radiation protection techniques, the risk of radiation exposure is minimal and equal to both genders.

Of course, a woman has to avoid radiation during pregnancy, and it is not true that the absences from the catheterization laboratory due to maternity can 'deskill' the doctor. You only have to look at the leading Interventionists in India to realize that many of them had no access to cath lab for years, between the time of training and starting the interventions.

An important obstacle remains the acceptance by the patients and public of a woman cardiologist, especially an Interventionist. From personal experience, I feel that the patients accept a competent doctor, regardless of their specialty and gender. It is true that there may be some initial resistance from the public and the opportunity to prove ones worth may be difficult to find. That is probably why more women opt to work in 
an Institute rather than foray into individual practice as cardiologists.

The greatest obstacle is however the attitude of male colleagues, often patronizing, frequently demeaning, towards their female equivalents. They often treat women as intellectual inferiors, expect them to be subservient and take credit for their achievements. But it is important to realize that it is not only women cardiologists who are exposed to this kind of behaviour. It is true of any member of a minority group who is posing a challenge to their equals. As with any situation leading to harassment, it is important to remain focused, keep calm and carry on!

Having said that, a man or woman who is confident of their own stature, does not discourage a fellow human being from developing. It is owing to these men of vision that women had been able to break the barriers and prove themselves.

Is it important that women should become cardiologists? Let us see...

Cardiac disease is in women is more challenging not only in terms of diagnosis but also in terms of treatment. Many randomized trials in cardiology had under representation of female patients and the lessons learnt from predominantly male Caucasian population were applied to the treatment of Indian women.

The unique physiological and pathophysiological features were not taken into consideration in evaluating the symptoms in women and generalizations were made that 'women had atypical symptoms and difficult to diagnose'- judgments made mostly by male physicians! It was indeed not until the 1970s, that there were clinical trials specifically looking at heart disease in women. It is interesting that the formal training of women in cardiology started in 1960s, which I am sure has provided the impetus for the attention in cardiological problems in women.

It is not only beneficial for the female patients, but the caring and compassionate

Attitude of women doctors is appreciated by all patients, men and women alike. It is time that women take their rightful place in all fields of society - not only cardiology but surgery etc.; not only medical field but academicals, political and leadership too. One should not interpret it as feminism to uphold basic human values and equality. We do however, need infrastructure to encourage women to fulfill their potential - not by positive discrimination but by providing equal opportunities and environment conducive to their development.

Lastly, it is up to women themselves to believe in their capabilities and demonstrate their worth.

“...But I have promises to keep, and miles to go before I sleep and miles to go before I sleep" - Robert Frost 